\title{
Size does not matter. The intrigue of giant adenomas: a true surgical challenge
}

\author{
Paolo Cappabianca • Luigi Maria Cavallo • \\ Domenico Solari • Oreste de Divitiis • \\ Carmela Chiaramonte • Felice Esposito
}

Received: 22 August 2014 / Accepted: 27 August 2014 / Published online: 11 September 2014

(C) Springer-Verlag Wien 2014

Pituitary surgery is an evolving specialty of modern neurosurgery that requires precise anatomical knowledge, technical skill, and integrated appreciation of pituitary pathophysiology. Over the years, this field has made a well-noticed advantage of the evolving ideas and surgical tools, amongst them, the endoscope. This last, with the advent of the concept of minimally invasive and keyhole surgery, gained popularity as the sole visualizing instrument in many neurosurgical approaches, above all those for pituitary lesions. Nowadays, the endoscopic transsphenoidal approach is commonly used in many centers throughout the world under the same indications as the conventional microsurgical technique [1]. Transsphenoidal surgery, with either microscopic or endoscopic technique, is currently adopted in more than $95 \%$ of surgical procedures to the sellar area and ca. $97 \%$ of all surgery for the treatment of pituitary adenomas [2-7]. The wider and panoramic view offered by the endoscope together with the proposals and contributions of many active groups has expanded its applicability to the removal of different "pure" supradiaphragmatic lesions [8-14]. Indeed, the extended endoscopic approach is increasingly adopted for the treatment of pathologies such as craniopharyngiomas, midline skull base meningiomas, chordomas, and other skull base lesions. Though it has been reported that the extended endonasal approach may offer a greater extent of resection also in the case of pituitary macroadenomas with suprasellar symmetric and/or

P. Cappabianca $(\bowtie) \cdot$ L. M. Cavallo $\cdot$ D. Solari $\cdot$ O. de Divitiis $\cdot$ C. Chiaramonte

Department of Neurosciences, Odontostomatological \& Reproductive Sciences, Division of Neurosurgery, Università degli Studi di Napoli Federico II, Via Pansini 5, 80131 Naples, Italy e-mail: paolo.cappabianca@unina.it

F. Esposito

Department of Neurosciences, Division of Neurosurgery, Università degli Studi di Messina, Messina, Italy asymmetric extension, recurrent or residual dumbbell-shaped adenomas and/or fibrous macroadenomas, once considered all amenable to open transcranial surgery only [15]. The same principles are valid in cases of giant adenomas, where the extended approach has proved to facilitate, in most instances, a wider lesion exposure just after the dural opening over the sellar-suprasellar space, thus avoiding any retraction of neurovascular structures [16-19]. However, there are conditions that could render more troublesome the transsphenoidal approach, either related to the anatomy of the surgical route or to the inner features of the lesion itself, i.e., the size of the sella, its degree of ossification, the size and the pneumatization of the sphenoid sinus, and/or carotid arteries position and shape $[1,6,20,21]$.

On the other hand, transcranial surgery should be preferred when tumors present with extensive intracranial invasion, with asymmetric lateral development, into the anterior cranial fossa or lateral or posterior extension into the middle and posterior cranial fossa, particularly if major vessel involvement is present and/or whether transsphenoidal surgery has been already unsuccessful, and in these regards, several authors have reported surgical strategy and results, properly addressing indications, pros, and cons [22-24].

When perceiving this controversial scenario, we moved backward through our series and analyzed the decisionmaking process, i.e., surgical approach choice, in those special-featured adenomas (giant, asymmetric, dumb-bell shaped). Although it is not possible to define a unique paradigm of management, we could thread a common line of attitude we have been relying on. In the attempt of not debating or comparing data or surgical techniques, we would like report several considerations in regards.

Tumors that achieve a diameter of $4 \mathrm{~cm}$ or greater are considered "giant" adenomas [16-19, 22, 23]; they usually determine chiasm and/or optic pathway compression, mass effect, and seldom invade cavernous sinus. Peerly, it has to be 
Fig. 1 Schematic drawings illustrating the sagittal view of the different growth paths of a giant pituitary adenoma: a lesion extending into the sphenoid sinus cavity down to the floor of nasal cavities; b lesion extending upward in the intracranial compartment compressing the chiasm/optic pathway, the third ventricle, and the other surrounding suprasellar neurovascular structures
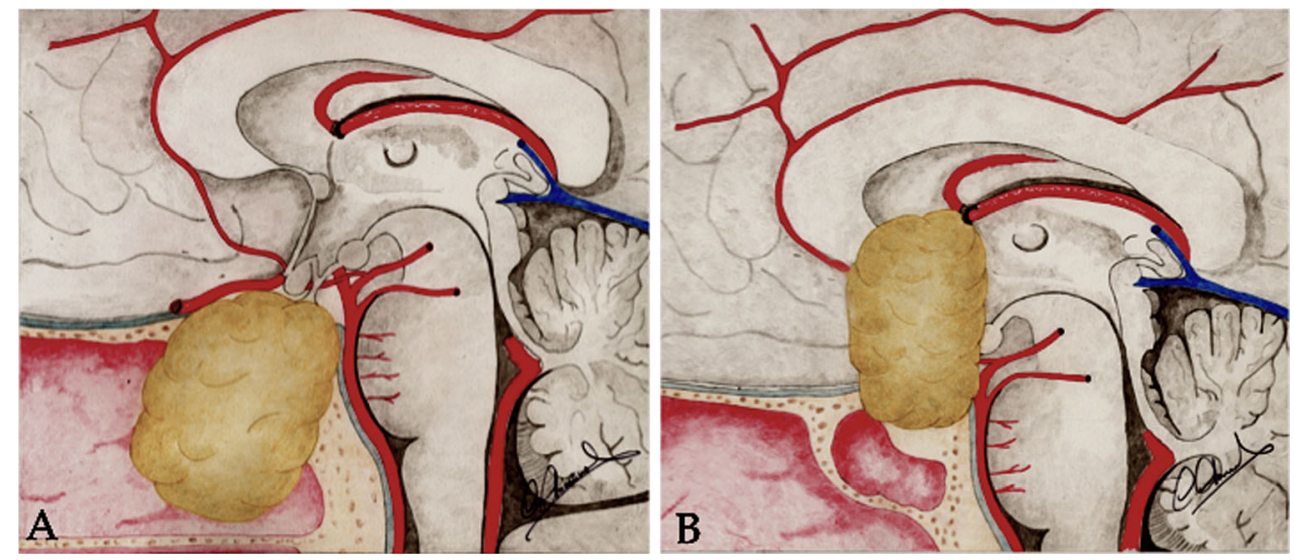

said that these lesions differ from large adenomas [17], which despite similar inner features and tendency to invasiveness do not harm neurovascular structures as giant adenomas do. Indeed, 4-cm-diameter or superior lesions, extending in the sphenoid sinus, or even down into the nasal cavities, do not require the same technical expertise of a same-sized lesion that extends upward in the suprasellar area, compressing the chiasm and/or the third ventricle, eventually breaching the diaphragm and/or stretching the surrounding neurovascular structures (Fig. 1). Although adenomas expand without direct brain tissue infiltration, the lateral extent could represent a peculiar aspect when choosing the surgical management strategy. A vertical sprout of the tumor, mostly on the midline, does not raise the same surgical problems as an eccentric growth, entering into the lateral aspects of anterior and/or middle cranial fossae. It cannot be underestimated the mass effect that results from compression of perforating vessels of paraventricular area and/or eventual intrusion into ventricle cavities (Fig. 2). As well, broad-based tumors extending into cavernous sinuses do not present such a troublesome management as do adenomas encroaching the supraclinoid ICA and/ or extending laterally to the optic nerves.

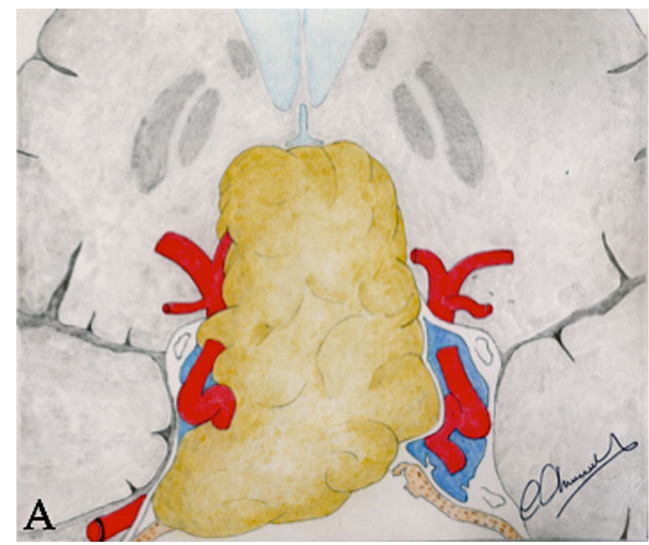

Fig. 2 Schematic drawings illustrating the coronal view of the different growth paths of a giant pituitary adenoma: a lesion extending upward mainly on the midline, occupying the suprasellar area up to compress the floor of the third ventricle; $\mathbf{b}$ lesion extending upward with eccentric
Even though large is different from giant, in the regards to the matter we are discussing, i.e., pituitary adenomas of big size, it is worth saying that "size does not matter" and attention should be targeted primarily to the pattern of growth of neoplasms. In our school, we advocate the endoscopic transsphenoidal approach, extended or not, for pituitary adenomas mainly developing along their vertical axis, not only growing downward in the sphenoid sinus, but also for those lesions extending mostly in the intracranial compartment, these latter representing a true surgical challenge, the real giant adenomas. Pituitary tumors represent biologically, endocrinologically, and pathologically a heterogeneous group of lesions, and the surgical procedure for the removal of a giant pituitary adenoma, regardless the hormonal status, should be mainly targeted to achieve the relief of mass effect, the preservation or restoration of normal neurologic function, and the decompression of the pituitary gland, thereby improving or preserving residual hormonal function, just as for a common macroadenoma.

We have to admit that the complete removal of giant adenomas represents a very uncommon outcome [16-19, 22, 23 ] and this permits us to stress another issue concerning the

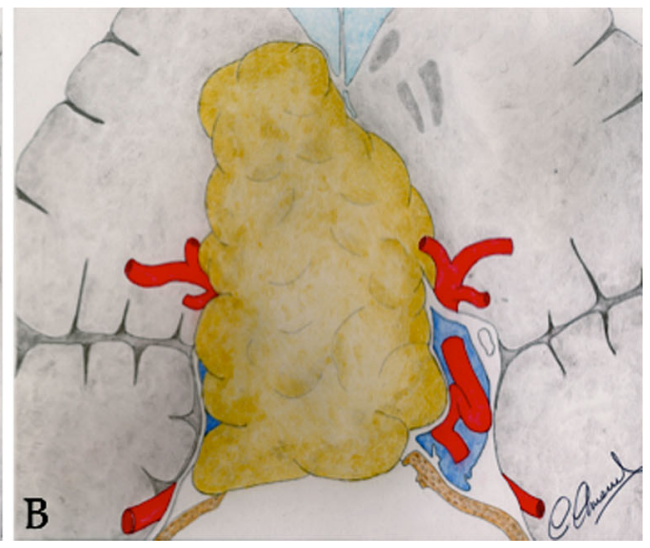

sprout into the paraventricular space, encroaching main vessels, i.e., internal carotid artery, middle carotid artery, and their branches, and compressing perforating vessels of basal ganglia and internal capsule 
surgical management of these lesions, i.e., the intralesional hemorrhage of residual tumor, which often results in tremendous complications, and seldom to death. It stands clear though that surgical management of these so-featured giant pituitary adenomas represents a major surgical challenge; accordingly, different kinds and rates of complications should be considered regardless the approach. Such surgical deeds require careful and specific postoperative management and long-term patient follow-up, which can make the difference between a satisfactory and a poor result. A patient can be operated on successfully, but the outcome may not be as brilliant as the surgical procedure, if mutual exchange amongst different specialties expertise is not created nor implemented.

After a long experience with the endoscopic endonasal technique, we adopted this approach as a viable strategy for the management of this subset of "intracranial" giant pituitary adenomas, in which at least $4 \mathrm{~cm}$ of the lesion is surrounded by brain tissue and not by nasal and paranasal sinuses. Along the specific case selection, our decision-making process accounts on a detailed preoperative evaluation of surgical risks as related to the lesion features, through the definition of coronal and sagittal relationships, the extension into anterior, middle, or posterior cranial fossae.

Nowadays, the Naples school policy for the management of giant pituitary adenomas is to adopt the endoscopic endonasal route, with either standard or extended variations as first choice unless a tumor presents significant intracranial extension that results out of the visibility and maneuverability of the endoscopic endonasal route. In these cases, we agree with the indications of the use of transcranial route, which has been clearly defined over the time, bearing in mind that, also via this corridor, leaving residual tumor behind exposes to tremendous risk of lesion hemorrhagic infarction.

Only a reasonable risk can be borne by the patient in terms of complications and postoperative morbidity; the surgeon must always attempt a "maximum-allowed" surgical outcome, but at the same time always must remember that a wide variety of different options - medical, surgical, and radiotherapyare now effective treatment in terms of long-term results. His/ her mind should be forged to relate the goal of surgery to the patient's needs, selecting the best option for the actual condition of the patient among all the options available, surgical or otherwise.

Conflict of interest statement All authors certify that they have no affiliations with or involvement in any organization or entity with any financial interest (such as honoraria; educational grants; participation in speakers' bureaus; membership, employment, consultancies, stock ownership, or other equity interest; and expert testimony or patent-licensing arrangements), or non-financial interest (such as personal or professional relationships, affiliations, knowledge or beliefs) in the subject matter or materials discussed in this manuscript.

Paolo Cappabianca

on behalf of the co-authors

\section{References}

1. Cappabianca P, Cavallo LM, de Divitiis O, Esposito F (2010) Pituitary surgery. In: DeGroot LJ, Jameson JL (eds) Endocrinology, 6th edn. Saunders Elsevier, Philadelphia, pp 358-376

2. Jane JA Jr, Thapar K, Kaptain GJ, Maartens N, Laws ER Jr (2002) Pituitary surgery: transsphenoidal approach. Neurosurgery 51(2): 435-442, discussion 442-434

3. Laws ER, Jane JA Jr (2001) Pituitary tumors-long-term outcomes and expectations. Clin Neurosurg 48:306-319

4. McLaughlin N, Eisenberg AA, Cohan P, Chaloner CB, Kelly DF (2013) Value of endoscopy for maximizing tumor removal in endonasal transsphenoidal pituitary adenoma surgery. J Neurosurg 118(3):613-620

5. McLaughlin N, Laws ER, Oyesiku NM, Katznelson L, Kelly DF (2012) Pituitary centers of excellence. Neurosurgery 71(5):916-924, discussion 924-916

6. Cappabianca P, de Divitiis E (2004) Endoscopy and transsphenoidal surgery. Neurosurgery 54(5):1043-1048, discussions 1048-1050

7. Laws ER, Lanzino G (eds) (2010) Transsphenoidal surgery. Saunders Elsevier, Philadelphia

8. Cappabianca P, Cavallo LM, Esposito F, de Divitiis O, Messina A, de Divitiis E (2008) Extended endoscopic endonasal approach to the midline skull base: the evolving role of transsphenoidal surgery. In: Pickard JD, Akalan N, Di Rocco C, Dolenc VV, Lobo Antunes J, Mooij JJA, Schramm J, Sindou M (eds) Advances and technical standards in neurosurgery. Springer, New York, pp 152-199

9. Cavallo LM, de Divitiis O, Aydin S, Messina A, Esposito F, Iaconetta G, Talat K, Cappabianca P, Tschabitscher M (2007) Extended endoscopic endonasal transsphenoidal approach to the suprasellar area: anatomic considerations - part 1. Neurosurgery 61:ONS-24-ONS-34

10. Cavallo LM, Messina A, Cappabianca P, Esposito F, de Divitiis E, Gardner P, Tschabitscher M (2005) Endoscopic endonasal surgery of the midline skull base: anatomical study and clinical considerations. Neurosurg Focus 19(1):E2

11. de Divitiis E, Cavallo LM, Cappabianca P, Esposito F (2007) Extended endoscopic endonasal transsphenoidal approach for the removal of suprasellar tumors: part 2. Neurosurgery 60(1):46-58, discussion 58-59

12. Kassam A, Snyderman CH, Mintz A, Gardner P, Carrau RL (2005) Expanded endonasal approach: the rostrocaudal axis. Part II. Posterior clinoids to the foramen magnum. Neurosurg Focus 19(1):E4

13. Kassam A, Snyderman CH, Mintz A, Gardner P, Carrau RL (2005) Expanded endonasal approach: the rostrocaudal axis. Part I. Crista galli to the sella turcica. Neurosurg Focus 19(1):1-12, E3

14. de Divitiis E, Cappabianca P, Cavallo LM (2002) Endoscopic transsphenoidal approach: adaptability of the procedure to different sellar lesions. Neurosurgery 51(3):699-705, discussion 705-707

15. Di Maio S, Cavallo LM, Esposito F, Stagno V, Corriero OV, Cappabianca P (2011) Extended endoscopic endonasal approach for selected pituitary adenomas: early experience. J Neurosurg 114(2):345-353

16. de Paiva Neto MA, Vandergrift A, Fatemi N, Gorgulho AA, Desalles AA, Cohan P, Wang C, Swerdloff R, Kelly DF (2010) Endonasal transsphenoidal surgery and multimodality treatment for giant pituitary adenomas. Clin Endocrinol (Oxf) 72(4):512-519

17. Juraschka K, Khan OH, Godoy BL, Monsalves E, Kilian A, Krischek B, Ghare A, Vescan A, Gentili F, Zadeh G (2014) Endoscopic endonasal transsphenoidal approach to large and giant pituitary adenomas: institutional experience and predictors of extent of resection. $\mathrm{J}$ Neurosurg 121(1):75-83

18. Komotar RJ, Starke RM, Raper DM, Anand VK, Schwartz TH (2012) Endoscopic endonasal compared with microscopic transsphenoidal and open transcranial resection of giant pituitary adenomas. Pituitary 15(2):150-159 
19. Koutourousiou M, Gardner PA, Fernandez-Miranda JC, Paluzzi A, Wang EW, Snyderman CH (2013) Endoscopic endonasal surgery for giant pituitary adenomas: advantages and limitations. J Neurosurg 118(3):621-631

20. Zada G, Du R, Laws ER Jr (2011) Defining the "edge of the envelope": patient selection in treating complex sellar-based neoplasms via transsphenoidal versus open craniotomy. J Neurosurg 114(2):286-300

21. Zada G, Cappabianca P (2010) Raising the bar in transsphenoidal pituitary surgery. World Neurosurg 74(4-5):452-454

22. Mortini P, Barzaghi R, Losa M, Boari N, Giovanelli M (2007) Surgical treatment of giant pituitary adenomas: strategies and results in a series of 95 consecutive patients. Neurosurgery 60(6):993-1002, discussion 1003-1004

23. Goel A, Nadkarni T, Muzumdar D, Desai K, Phalke U, Sharma P (2004) Giant pituitary tumors: a study based on surgical treatment of 118 cases. Surg Neurol 61(5):436-445, discussion 445-436

24. Recinos PF CRG, Brem H, Q-H A (2012) Transcranial surgery for pituitary macroadenomas. In: Quinones-Hinojosa A (ed) Schmidek and Sweet: operative neurosurgical techniques. Indications, methods, and results. Sixth edition, 6th edn. Saunders Elsevier, Philadelphia, pp 280-291, vol 1

\section{Comment}

Prof Cappabianca's unit in Naples has a long track record as one of the most important teachers of the endoscopic transsphenoidal route to sella lesions, and certainly one of the most scientific. Hence, anything that is said by him must be considered with due respect.

Here he sets out his philosophy for the approach to the difficult, huge tumors in the area, which challenge even the experienced. Essentially it is a plea for the multi-disciplinary team, in order to consider all the options to the best benefit of the patient.

Mike Powell

London, UK 